\title{
Is the evaluation of quality of life in NSCLC trials important? Are the results to be trusted?
}

\author{
Vera Hirsh* \\ Department of Medical Oncology, McGill University Health Centre, Royal Victoria Hospital, Montreal, OC, Canada
}

Edited by:

Karen L. Reckamp, City of Hope

Comprehensive Cancer Center, USA

\section{Reviewed by:}

Jae Yul Kim, City of Hope

Comprehensive Cancer Center, USA

Jhanelle Elaine Gray, H. Lee Moffitt

Cancer Center and Research Institute, USA

\section{*Correspondence:}

Vera Hirsh, Department of Medical

Oncology, McGill University Health Centre (MUHC), Royal Victoria

Hospital, 687 Pine Avenue West,

Room E3.53, Montreal, QC, H3A 1A1,

Canada

e-mail:vera.hirsh@muhc.mcgill.ca
The majority of patients with non-small cell lung cancer present at the time of diagnosis with stage IV metastatic disease and they experience 2 or more disease-related symptoms. These symptoms may have a negative impact on their health-related quality of life (HR QOL). Data has shown many of these patients prefer a therapy to improve their symptoms rather than receive a therapy which slightly prolongs their survival without improving their symptoms. The improvement of disease-related symptoms on a specific drug or regimen augments the significance of prolongation of the progression-free survival or the response rate as well as symptom worsening. The choice of the questionnaires to evaluate patients' reported outcomes and HR OOL benefits and the methods of collecting the data and their interpretations are very important. Only if the data are collected and analyzed properly will they be meaningful and can then be viewed as components that add the total value to a treatment and provide a comprehensive picture of the benefits and risks of a certain anticancer therapy.

Keywords: HR QOL, symptoms, data collection, metastatic NSCLC, clinical trials

\section{INTRODUCTION}

Lung cancer is the leading cause of cancer death worldwide for both men and women (1). A majority of these patients present at the time of diagnosis with metastatic disease. Approximately $90 \%$ of patients with advanced non-small cell lung cancer (NSCLC) experience two or more disease-related symptoms such as cough, dyspnea, pain, anorexia, or fatigue (2). These symptoms in turn can cause psychological distress and may have a negative impact on a patient's health-related quality of life (HR QOL). High degrees of psychological distress influence the emotional wellbeing in both patients and their families. In one survey, $68 \%$ of patients preferred a therapy that would improve disease-related symptoms without prolonging their life as opposed to treatment(s) that slightly prolonged their survival without improving symptoms (3).

A patient's well-being can be affected both through symptomcontrol, treatment-related toxicity, and treatment efficacy. Therefore, treatments which can decrease the tumor burden and growth, and be less toxic, are very important for patients with advanced NSCLC $(4,5)$. It is of the utmost importance for these patients to preserve their independence and not be dependent on their loved ones feeling like a burden at the end of their lives (6-8).

Some studies suggest a link between tumor response and improvement of symptoms such as cough, dyspnea, chest pain, and also systemic symptoms such as fever, anorexia, and weight loss (911). The improvements in symptoms further augment the significance of good response rates or prolonged PFS. As the median OS of most of the patients with metastatic NSCLC is modest (around 1 year), with specific new targeted agents it approaches 2 years, therefore HR QOL and patients' reported outcomes (PROs) carry high importance and thus will be reviewed here.

\section{COLLECTION OF THE DATA}

Patients' reported outcomes and HR QOL benefits are usually assessed during clinical trials using the self-administered cancerspecific European Organization for Research and Treatment of Cancer (EORTC) questionnaires QLQ C30 (12), the lung cancerspecific EORTC QLQ LC13 (13), and the Euro QOL EQ-5D (14) questionnaire (in afatinib LUX LUNG phase 3 trials or crizotinib phase 3 trials) or functional assessment of cancer therapy-lung (FACT-L) (15) (functional assessment of cancer treatment in lung cancer) questionnaire (i.e., in IPASS phase 3 trial with gefitinib). The QLQ C30 questionnaire consists of five functional scales (physical, role, cognitive, emotional, and social functioning), three symptom scales (fatigue, pain, and nausea/vomiting), a global health status/QOL scale, and single items, i.e., dyspnea, loss of appetite, constipation, diarrhea, sleep disturbance, and financial impact. The QLQ LC13 questionnaire incorporates one multi-item scale to assess dyspnea and a series of single items assessing cough, pain, sore mouth, dysphagia, peripheral neuropathy, alopecia, and use of pain medication.

For each scale/item, a linear transformation is applied to standardize the raw score on a range from 0 to 100 with 100 representing the best possible function/QOL for functional scales, and the highest burden of symptoms for symptom scales and symptom items. A 10-point change in an item or domain is perceived to be clinically meaningful (16). The percentage of patients who are classified as improved ( $\geq 10$-point increase for functioning scales and $\geq 10$-point reduction for symptom domains or items from baseline scores) with respect to each of the questionnaires is examined (16). In addition, the time-to-deterioration of an item/domain score is defined as the item from randomization to the first appearance of a score that is 10 points or more lower or higher than the baseline 
score ( $\geq 10$-point reduction for functioning scales and $\geq 10$-point increase for symptom scales or items).

The EQ-5D is a disease-generic questionnaire that comprises the EQ-5D and EQ-visual analog scale (VAS). The EQ-5D measures five dimensions of health (mobility, self-care, usual activities, pain/discomfort, and anxiety/depression). Each dimension comprises three levels (no problems, some/moderate problems, and extreme problems). Utility scores range from 0 to 1 and are calculated from the five EQ-5D items scores using the United Kingdom preference weights (17). The EQ-VAS records the patient's self-rated health status on a vertical, graduated (0-100) VAS.

Functional assessment of cancer therapy-lung questionnaire (version 4) comprises 36 items across 5 domains/categories: physical, social, family, emotional, and functional well-being. The Lung cancer subscale consists of symptoms, cognitive function, and regret of smoking. Scores range from 0 (not at all) to 4 (very much) (15).

Each protocol specifies a schedule for questionnaires to be completed (at baseline, every 2-4 weeks, at the end of the treatment visit, and during the first follow-up visit). The use of concomitant medications is assessed at the baseline and during the trial, especially analgesic use, anti-anxiety/depression medications, $\mathrm{O}_{2}$ use, etc.

\section{INTERPRETATION OF THE RESULTS}

Patients must answer the questionnaires prior to learning the results of their tests (scans) from their physicians in order to obtain reliable results. Help with the questionnaires should be available by knowledgeable staff in the clinic or hospital. Since patients must fill out the questionnaire by themselves, supervision of this procedure in order to ensure objectivity is important. Attention should be paid to the baseline scores. In randomized trials, are they well-balanced? Are they low (i.e., low burden of symptoms) or high (i.e., high burden of symptoms)? If the baseline scores are low, the percentage of patients with improved symptoms on certain anticancer treatments might be difficult to find. Delay of the symptom deterioration is usually of high importance. The longitudinal analysis which looks at symptoms and HR QOL over time (at different visit intervals) might be informative.

The compliance of patients a propos to the completion of their questionnaires must be reported at the baseline and also during the study. The compliance during the study should remain at $\geq 80 \%$ in order to interpret the results appropriately. In the case of EORTC questionnaires, both EORTC QLQ LC13 and QLQ C30 have to be analyzed to get a complete picture not only of lung cancer-related symptoms, but also of symptoms related to cancer treatment toxicities. The patients' symptoms are treated by analgesics, cough suppressants, $\mathrm{O}_{2}$, anti-depressants, appetite stimulating agents, etc., and they all have to be incorporated in the final analysis. Other factors such as patient's performance status (improving or deteriorating), weight loss, and special emotional counseling are of great value and can influence patients' HR QOL.

\section{CONCLUSION}

Patients' reported outcomes and health-related quality of life outcomes are important parameters of the evaluation of new drugs or regimens of patients in advanced NSCLC, but only if the data are collected and analyzed correctly. They should be viewed as components of the total value of a treatment. They should provide, together with the other primary and secondary endpoints, a comprehensive picture of the benefits and risks of anticancer therapies for patients with metastatic NSCLC. This is the position taken by the Food and Drug Administration (18) and the European Medicine Agency $(19,20)$.

Dedicated personnel are required for this time-consuming process of collecting and analyzing the PROs and HR QOL data. The delivery of reliable results from these questionnaires requires the team work of knowledgeable and devoted workers. Consequently enabling patients with advanced NSCLC to feel more comfortable and independent during the last months or years of their life becomes a very important task in their treatment.

\section{REFERENCES}

1. The National Cancer Institute. Stage IV NSCLC Treatment. The National Institute (2012). Available from: http://www.cancer.gov/cancertopics/pdq/ treatment/non-small-cell-lung//healthprofessional/page1 1

2. Socinski MA, Morris DE, Masters GA, Lilenbaum R; American College of Chest Physicians. Chemotherapeutic management of stage IV non-small cell lung cancer. Chest (2003) 123:226S-43S. doi:10.1378/chest.123.1_suppl.226S

3. Cella D, Peterman A, Hudgens S, Webster K, Socinski MA. Measuring the side effects of taxane therapy in oncology: the functional assessment of cancer therapy-taxane (FACT-taxane). Cancer (2003) 98:822-31. doi:10.1002/cncr. 11578

4. Therasse P, Arbuck SG, Eisenhauer EA, Wanders J, Kaplan RS, Rubinstein L, et al. New guidelines to evaluate the response to treatment in solid tumors. European Organization for Research and Treatment of Cancer, National Cancer Institute of the United States, National Cancer Institute of Canada. J Natl Cancer Inst (2000) 92:205-16. doi:10.1093/jnci/92.3.205

5. Silvestri G, Pritchard R, Welch HG. Preferences for chemotherapy in patients with advanced non-small cell lung cancer: descriptive study based on scripted interviews. BMJ (1998) 317:771-5. doi:10.1136/bmj.317.7161.771

6. McPherson CJ, Wilson KG, Lobchuk MM, Brajtman S. Self-perceived burden to others: patient and family caregiver correlates. J Palliat Care (2007) 23:135-42.

7. McPherson CJ, Wilson KG, Murray MA. Feeling like a burden to others: a systematic review focusing on the end of life. Palliat Med (2007) 21:115-28. doi:10.1177/0269216307076345

8. Johnson JO, Sulmasy DP, Nolan MT. Patients' experiences of being a burden on family in terminal illness. J Hosp Palliat Nurs (2007) 9:264-9. doi:10.1097/01. NJH.0000289656.91880.f2

9. de Marinis F, Pereira JR, Fossella F, Perry MC, Reck M, Salzberg M, et al. Lung Cancer Symptom Scale outcomes in relation to standard efficacy measures: an analysis of the phase III study of pemetrexed versus docetaxel in advanced non-small cell lung cancer. J Thorac Oncol (2008) 3:30-6. doi:10.1097/JTO. 0b013e31815e8b48

10. Mayer RL. Hunting accidents. South Med J (1991) 84:1284. doi:10.1097/ 00007611-199110000-00035

11. Tanvetyanon T, Soares HP, Djulbegovic B, Jacobsen PB, Bepler G. A systematic review of quality of life associated with standard chemotherapy regimens for advanced non-small cell lung cancer. J Thorac Oncol (2007) 2:1091-7. doi:10.1097/JTO.0b013e31815cff64

12. Catravas GN, Takenaga J, McHale CG. Effect of chronic administration of morphine on monoamine oxidase activity in discrete regions of the brain of rats. Biochem Pharmacol (1977) 26:211-4. doi:10.1016/0006-2952(77)90305-7

13. Bergman B, Aaronson NK, Ahmedzai S, Kaasa S, Sullivan M. The EORTC QLQLC13: a modular supplement to the EORTC core quality of life questionnaire (QLQ-C30) for use in lung cancer clinical trials. EORTC study group on quality of life. Eur J Cancer (1994) 30A:635-42. doi:10.1016/0959-8049(94)90535-5

14. Hancock E. Crisis intervention in a newborn nursery intensive care unit. Soc Work Health Care (1976) 1:421-32. doi:10.1300/J010v01n04_03

15. Cella DF, Tulsky DS, Gray G, Sarafian B, Linn E, Bonomi A, et al. The Functional Assessment of Cancer Therapy Scale: development and validation of the general measure. J Clin Oncol (1993) 11:570-9. 
16. Osoba D, Rodrigues G, Myles J, Zee B, Pater J. Interpreting the significance of changes in health-related quality of life scores. J Clin Oncol (1998) 16: 139-44.

17. Hirsh V, Cadranel J, Cong XJ, Fairclough D, Finnern HW, Lorence RM, et al. Symptom and quality of life benefit of afatinib in advanced non-small cell lung cancer patients previously treated with erlotinib or gefitinib: results of a randomized phase IIb/III trial (Lux-Lung 1). J Thorac Oncol (2013) 8:229-37. doi:10.1097/JTO.0b013e3182773fce

18. ASCO/FDA Lung Cancer Endpoints Workshop. Executive Summary of Workshop Discussion: Workshop Summary on Endpoints for Approval of Cancer Drugs for Lung Cancer (2003). Available from: http://www.fda.gov/downloads/Drugs/DevelopmentApprovalProcess/ DevelopmentResources/CancerDrugs/ucm094744.pdf

19. (EMEA) EMA. Guideline on the Evaluation of Anticancer Medicinal Products in Man (2005). Available from: http://www.emea.europa.eu/docs/en_GB/ document_library/Scientific_guideline/2009/12/WC500017748.pdf

20. (EMEA) EMA. Reflection Paper on the Regulatory Guidance for the Use of Health-Related Quality of Life (HRQL) Measures in the Evaluation of
Medicinal Products (2005). Available from: http://www.ispor.org/workpaper/ emea-hrql-guidance.pdf

Conflict of Interest Statement: The author declares that the research was conducted in the absence of any commercial or financial relationships that could be construed as a potential conflict of interest.

Received: 28 April 2014; accepted: 18 June 2014; published online: 03 July 2014.

Citation: Hirsh V (2014) Is the evaluation of quality of life in NSCLC trials important? Are the results to be trusted? Front. Oncol. 4:173. doi: 10.3389/fonc.2014.00173

This article was submitted to Thoracic Oncology, a section of the journal Frontiers in Oncology.

Copyright (c) 2014 Hirsh. This is an open-access article distributed under the terms of the Creative Commons Attribution License (CC BY). The use, distribution or reproduction in other forums is permitted, provided the original author(s) or licensor are credited and that the original publication in this journal is cited, in accordance with accepted academic practice. No use, distribution or reproduction is permitted which does not comply with these terms. 